Article

\title{
A Tightly Coupled GIS and Spatiotemporal Modeling for Methane Emission Simulation in the Underground Coal Mine System
}

\author{
Hui Liu ${ }^{1}{ }^{1}$, Shanjun Mao ${ }^{1, *}$, Mei Li $^{1}$ and Shuangyong Wang ${ }^{2}$ \\ 1 Institute of Remote Sensing and Geographic Information System, Peking University, Beijing 100871, China; \\ huil@pku.edu.cn (H.L.); mli@pku.edu.cn (M.L.) \\ 2 Beijing LongRuan Technologies Inc., Beijing 100190, China; wangshuangyong@longruan.com \\ * Correspondence: sjmao_@pku.edu.cn; Tel.: +86-10-62755420
}

Received: 26 March 2019; Accepted: 7 May 2019; Published: 10 May 2019

check for updates

\begin{abstract}
Mine safety is of primary concern in the underground coal mining system. At present, there is a lack of an efficient platform to manage the numerical simulation procedure and inherent spatiotemporal data for coal mine disasters. This necessitates the coupling of spatiotemporal model with geographic information system (GIS) in practical application. Here, a novel spatiotemporal model tightly coupled with GIS is presented to improve the model-data integration. Such tight coupling is achieved by developing a lattice Boltzmann method (LBM) based turbulent model with an underlying shared FluentEntity model within the LongRuanGIS platform. The case study and comparison with the traditional computational fluid dynamics (CFD) method demonstrated that the platform is capable and effective in providing functionalities for lattice domain decomposition, simulation, visualization and analyses, as well as improving the computational efficiency. The proposed approach and platform, promising for the disaster prevention, offer a template for future GIS-Model integration and also applicable for other underground coal mine disasters.
\end{abstract}

Keywords: mine safety; GIS-coupled; spatiotemporal model; LBM; methane gas emission

\section{Introduction}

Mine safety issue has long been a paramount concern in the underground coal mining business, since mine accidents can lead to serious injuries for personnel, substantial economic losses, and delayed production. Numerical modelling offers a useful tool for prediction and control of various disasters in mine workings. The principles of computational fluid dynamics are widely applied to the underground coal mine systems and numerous computational fluid dynamics (CFD) methods are utilized to simulate various ventilation-related safety and health issues [1-4]. It is remarkably noted that the procedure of CFD simulation interrelated with geometric modeling and numerical calculation, is inherently geospatial. The spatiotemporally simulated data requires effective management and analysis, which is essential to reduce the risk associated with mine accidents. However, the current simulations of coal mine disasters mostly depend on the independent third-party numerical simulation software, and there is no professional simulation platform developed for specific problems. For instance, numerical platforms such as Fluent, COSFLOW, FLAC3D, and AutoReaGas are utilized by many researchers in simulating gas emission in mining face, the hole wall, and other ventilation related activities [5-8]. There is a lack of an integrative and effective platform to store and manage the massive amount of spatiotemporal simulated data, as well as the data visualization and analysis, which makes the whole analysis procedure difficult to direct the on-site production. According to researches proposed by Goodchild, one of the key challenges in the application of physics based models is 
the lack of a platform for efficient prototyping of model simulations, evaluation of a-priori parameters, and for simulation, analysis, and visualization $[9,10]$. Fortunately, geographic information system (GIS) technology is able to acquire, develop, and interpret the complex spatial datasets used for mining and the earth sciences. [11], which is suitable to provide an ideal platform to organize the numerical simulation procedure as well as data management. Therefore, coupling GIS with physics based numerical models is of paramount significance.

Application of GIS in mining is a relatively new and fast evolving concept [12]. GIS technologies create efficiency and productivity opportunities in all aspects of mineral exploration and mining, which enables a mine operator to mine intelligently, efficiently, competitively, safely, and environmentally. In this way, GIS integrates exploration, operation, and environmental issues with mine management [13]. To date, many GIS-based systems for underground coal mining safety were developed. For example, a GIS-based monitoring and management system was developed for underground coal mining safety by Seda Şalap [14], and many researchers have conducted the modeling and risk assessment of mining-induced hazards based on GIS [15,16]. However, the system development is mostly based on the open source GIS framework and focused on information management and monitoring, which are limited to the display and query of the coal mine map [17], incapable of displaying the models of various disasters from the perspective of underlying physical mechanism $[18,19]$. Nowadays, the coupling of numerical modeling with GIS system has already been investigated in other environmental issues, and how to effectively integrate them is regarded as one of the most increasingly focused issues. It is noted that a great number of related research were carried out in the fields of geomechanics, environmental monitoring, and hydrology [20-23]. For instance, the integration of finite element simulation with GIS was investigated and applied in the tunnel engineering by Zhenping Liu [24]. Maohui Zhen studied the block gas diffusion process within GIS based on the open source CFD software OpenFOAM [25]. Junting Ma proposed finite element numerical simulation of the groundwater in the GIS technical platform [26]. Mar Alcaraz studied the configuration of geometry and parameterization for groundwater numerical models, and proposed a loosely coupled GIS and hydrogeological modeling platform [27]. Gopal Bhatt presented an open-source, platform independent, tightly coupled GIS and distributed hydrologic modeling platform (PIHMgis), which was aimed to improve the model-data integration [28]. However, the existing coupling modes mainly depend on the third-party professional software to implement the numerical simulation procedure, which requires data transformation in different platforms due to the independence of the traditional CFD methods with respect to the mesh generation and simulation procedure [29]. And this transition needs specific methodologies to adapt the geometries and alphanumerical data from the conceptual model to the numerical model for obtaining optimal numerical results. To overcome this gap and to make the integrated system more flexible, a more efficient way to integrate the numerical CFD model with the GIS is mandatory [30-32]. By comparing the existing CFD methods, it was demonstrated that the property of the unnecessary explicit mesh generation and the inherent simplicity of the algorithm make LBM significantly popular in CFD community [33-37], which is expected to be promising and more efficient to integrate with the GIS platform.

Therefore, this study aims to apply the coupling concept of GIS and numerical simulation in the underground mining for the first time by proposing an applicable numerical model based on the non-traditional lattice Boltzmann method (LBM). By considering the spatiotemporal characteristics of coal mining activities, major accidents, and its interrelated spatiotemporal data analysis, a robust and tight GIS-coupled spatiotemporal modeling system is a powerful and thorough solution to simulate the major accidents by providing more intuitive visualization, query, and analysis tools. Specifically, the system should: (i) perform numerical model, (ii) display the simulated field data with inherent geospatial data such as coal mine map, seamlessly, (iii) provide data storage, management and access of the surveillance data based on database management system, which allows the data verification and validation of the numerical model, (iv) provide managers and miners the access to 
large amount of location-based information by spatiotemporal query and analysis to guide the coal mine operation.

Longruan GIS (LrGIS) developed by our team, is professionally designed and ideally suited to assist mining professionals in meeting the complex challenges of running the mine operation. With tools to compile, process, display, analyze, and archive massive volumes of data, the LrGIS platform is increasingly applied in the business of mining industry in China, which allows us to develop the mathematical model and manage volumes of data through its secondary development mode [38]. Thus, this study chooses LrGIS as the supporting GIS software package, and it takes the methane gas emission as the case study, which is one of the most crucially important mine safety issues. It is worth noted that the numerical model can be extended and improved to simulate other mining activities, such as ventilation solution, mine fire, and methane explosion.

We performed the model coupling and numerical simulation from the following ways. First, the U-type ventilation system-15116 in Sijiazhuang coal mine is specified as the computational domain, and a novel turbulent LBM based velocity-concentration coupling model is proposed to investigate the spatiotemporal characteristics of the airflow behavior and the methane gas emission in a coal mine working face. Second, the numerical model is integrated with LrGIS platform via FluentEntity model, and the graphical representations of simulated field data as well as various map layers are demonstrated. From this, the spatial characteristics of methane distribution can be intuitively visualized, and detailed location-based information for the practical mining production can be provided by spatiotemporal query and analysis. Third, the numerical simulation results are verified by field measurements in Sijiazhuang coal mine and compared with traditional CFD methods, demonstrating the accuracy and reliability of the proposed model. Thus, the developed system can assist decision makers to simulate, understand, and forecast ventilation-related activities and its dynamic change inside the laneway, which is expected to be an efficient tool for improving and maintaining the health standards in the underground coal mining industry.

\section{Case Study}

A fully mechanized U-type working face (15116 laneway) in Sijiazhuang coal mine was selected as the physical prototype to implement the GIS-coupled spatiotemporal modeling, which is located in Shanxi province, China. This mine working face is selected for access to precisely and continuously recorded mine data. The layout of the working face laneway is shown in Figure 1. It has a working face zone, wind intake laneway, and wind outtake laneway with the rectangular cross-section of $4.2 \mathrm{~m}$ wide and $4 \mathrm{~m}$ high. The working face is $220 \mathrm{~m}$ long, while the wind intake and outtake laneways are all $600 \mathrm{~m}$ long.

According to the safety operation regulations in Sijiazhuang coal mine, the airflow quantity in the 15116 working face laneway is $53.3 \mathrm{~m}^{3} / \mathrm{s}$, which is calculated based on the requirement of the mine gas and carbon dioxide emission quantity, the temperature and the number of maximum miners in the working face area, and it has been checked by the maximum and minimum wind speed. The estimated methane emission flow rate is about $0.2 \mathrm{~m}^{3} / \mathrm{s}$. During the procedure of coal mining in the U-type laneway system, the working face is the main source of the methane gas emission. A large amount of the methane gas generated from the working face disperses with the pressing air from the wind inflow side, finally, part of it is removed through the wind inflow laneway, while the rest stays in the laneway space. During the delivering process, movement of methane coupled with the airflow exhibits a species transportation flow. Here, we have three model assumptions consistent with the published research [39]: (i) the airflow in the working face zone belongs to the turbulent flow; (ii) the airflow and methane gas are continuous medium gas; (iii) heat and mass transfer are ignored during the process of air flow. 


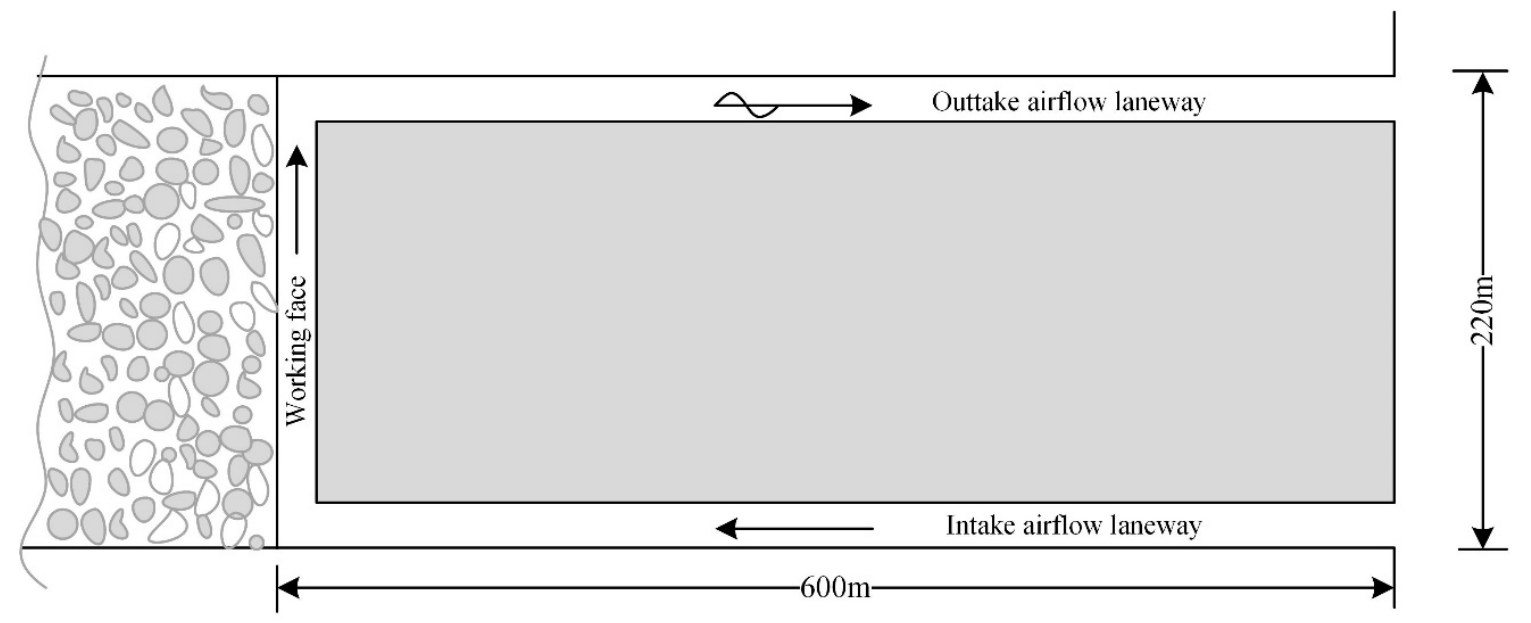

Figure 1. Layout of 15116 workface in Sijiazhuang mine.

\section{Model-GIS Coupling Strategy}

In this study, the numerical model and LrGIS platform are linked to achieve the model-GIS integration. Specifically, the proposed numerical model is the velocity-concentration coupled 2D LBM, which is integrated with LrGIS platform by developing the FluntEntity model, so that both GIS platform and model functions can access the geospatial simulation results. The GIS platform, the numerical model, and the integration strategies are described in detail in the following sections.

\subsection{LrGIS Platform}

LrGIS (Longruan GIS 3.2) is a professional coal mine GIS platform (Beijing LongRuan Technologies Inc.) with its own intellectual property right, which is widely applied in the business of mining industry in China and well supported by professional developers. It is well designed for coal mine system with respect to the geospatial features of coal mine laneway, ventilation network, and etc., and professionally focuses on large amount of mine spatial data, such as surveying, geology, hydrology reserves, transportation, ventilation network, mine design schedule. Besides, it fulfills the integrated management of massive spatial data and information sharing among different platforms, and provides flexible secondary development mode, such as API, DLL, ActiveX, and application template [40]. Therefore, LrGIS is suitable to perform GIS-numerical model integration in this study.

Despite all these advantages, these functions rely on inherent and advanced GIS capabilities, and there is a lack of defined conceptual model associated with spatiotemporal modeling to simulate various kinds of disasters to satisfy some actual needs, such as the methane gas emission simulation, the gas explosion prediction in emergency response, ventilation network design based on the pre-simulation, and mine fire simulation to guide miners to escape from the disaster and etc. The integration of the spatiotemporal modeling with GIS can provide great support for practical production needs. These inbuilt GIS functions are insufficient in terms of spatiotemporal modeling, because the data require specific treatments to be used in spatiotemporal modeling. In this study, explicit mesh creation is not needed, which is usually troublesome in traditional CFD method and inconsistencies of input geometries always lead to labor intensive and time-consuming process for mesh generation [41,42]. The integration mode proposed in this study avoids this problem and improves the computational efficiency.

\subsection{Mathematical Models}

The essential regularity of methane dispersion and its coupling with air flow is a key issue for the methane gas emission problem, and its flowing regulation belongs to viscous Newtonian fluid, which is governed by the Navier-Stokes (N-S) equations. There are many numerical approaches to 
solve the N-S equations, such as the traditional CFD methods and the LBM. Here the LBM based numerical method is adopted. In phase space, the Boltzmann equation is discretized in threefold, including space, time, and velocities. The movement and distributions of the fluid are described as particle distribution functions residing at the sites of a regular lattice of points, which encompasses the entire computational field. The particle distribution functions stand for the probability of particle presence with a specific velocity at each lattice or grid site. The macroscopic variables of the fluid, such as velocity or density, can be derived from these distribution functions.

The LBM consists of two fundamental steps, namely, the streaming-step and the collision-step. For every time step, distribution functions are distributed and streamed from each site to the neighboring sites in the streaming-step, and then the collision-step is conducted with the distribution functions relaxed towards a local equilibrium on the basis of the new macroscopic variables [32]. Here, the coupling flow of the methane gas and airflow belongs to the species transportation. The coupling model of the velocity and concentration based on 2D LBM was deduced, and the simulation procedure for velocity field and concentration field is presented. The Bossinesq approximation method is utilized to couple these two fields.

\subsubsection{Lattice Boltzmann Method for Velocity Field}

The LBM is commonly labelled as DdQq, where $\mathrm{d}$ stands for the space dimension and $\mathrm{q}$ is the number of microscopic lattice velocity directions. The possible nodes for 2D lattices are D2Q5, D2Q9. In this study, the D2Q9 model is employed to carry out the airflow velocity field, because it maintains good isotropy of the lattice. The airflow particles distribution on a lattice is shown in Figure 2a.

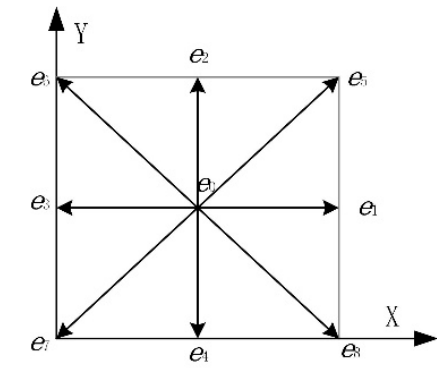

(a) Velocity field lattice (D2Q19)

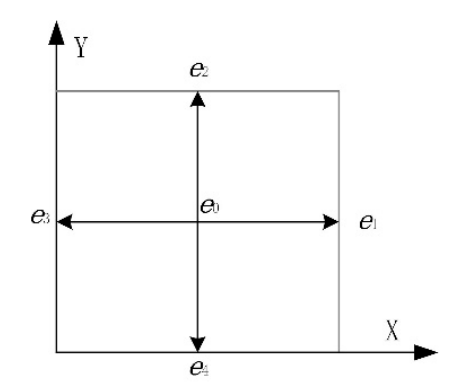

(b) Concentration field lattice (D2Q5)

Figure 2. Schematic views of particles distribution in $2 \mathrm{~d}$ lattice.

The fictitious fluid particles are subject to the lattice Boltzmann equation

$$
f_{i}\left(x+c e_{i} \Delta t, t+\Delta t\right)-f_{i}(x, t)=\Omega_{i}(f), \quad i=0,1, \ldots, 8,
$$

which describes the evolution of distribution function $f_{i}$ on Cartesian grids with a selective velocity $\boldsymbol{e}_{i}, c$ is the movement velocity, $\Omega_{i}(f)$ denotes the discrete collision operator, and $\Delta t$ is the time step. The complex collision operator is approximated by using the standard Bhatnagar-Gross-Krook (BGK) scheme [43], which states that the distribution functions is close to a local equilibrium distribution function $f_{i}^{e q}$ and relaxes toward this equilibrium with a characteristic time $\tau$. The evolution of the distribution functions using the BGK collision is described by the following equation:

$$
\Omega_{i}(f)=-\frac{1}{\tau}\left[f_{i}(x, t)-f_{i}^{e q}(x, t)\right]
$$


where $\tau$ is the relaxation factor (viscosity of fluid is related to the relaxation time), $f_{i}^{e q}$ depends on the density $\rho$ and velocity $u$ of the gas, and is typically defined as

$$
f_{i}^{e q}(x, t)=\omega_{i} \rho\left(1+\frac{\boldsymbol{e}_{i} \boldsymbol{u}}{c_{s}^{2}}+\frac{\left(\boldsymbol{e}_{i} \boldsymbol{u}\right)^{2}}{2 c_{s}^{4}}-\frac{u^{2}}{2 c_{s}^{2}}\right), \quad i=0,1, \ldots, 8,
$$

where $\omega_{i}$ is the model-dependent weight coefficient $c_{s}=\sqrt{R T}$ ( $R$ is the gas constant) is the lattice sound speed. For isothermal flows, $c_{S}$ is set to be $c / \sqrt{3}$ with $c=\Delta x / \Delta t$, where $\Delta x$ is the lattice spacing $(c=1$ in this paper). Through the Chapman-Enskog expansion, the macroscopic fluid density $\rho$, and velocity $\mathrm{u}$, can be derived as the zeroth and first order moments of $f_{i}$ respectively,

$$
\rho=\sum_{i=0}^{b-1} f_{i}, \quad \rho \boldsymbol{u}=\sum_{i=0}^{b-1} \boldsymbol{e}_{i} f_{i}
$$

The fluid pressure is defined directly as $p=c_{s}^{2} \rho$, the velocity set and the corresponding weight coefficients are defined as

$$
\begin{gathered}
\boldsymbol{e}_{i}=\left[\begin{array}{ccccccccc}
0 & 1 & 0 & -1 & 0 & 1 & -1 & -1 & 1 \\
0 & 0 & 1 & 0 & -1 & 1 & 1 & -1 & -1
\end{array}\right] \\
\omega_{i}= \begin{cases}4 / 9, & i=0 \\
1 / 9, & i=1,2,3,4 \\
1 / 36, & i=5,6,7,8\end{cases}
\end{gathered}
$$

The above model can deduce the Navier-Stokes equation, which describes airflow regularity in the laneway.

$$
\begin{gathered}
\frac{\partial \rho}{\partial t}=-\nabla \cdot(\rho \boldsymbol{u}) \\
\frac{\partial \rho}{\partial t}+\nabla p+\nabla \cdot(\rho \boldsymbol{u})=\nabla\left[\rho v\left(\nabla \boldsymbol{u}+(\nabla \boldsymbol{u})^{T}\right)\right]
\end{gathered}
$$

\subsubsection{Concentration Field through a Coupled Model}

A coupled model is used to simulate the methane concentration field, where a D2Q9 lattice with a BGK collision operator is also used to solve the velocity and density, while the methane gas concentration is solved on a smaller and separate D2Q5 lattice. The distribution of concentration particles on a lattice is shown in Figure $2 b$.

The evolution equation for the methane concentration field is described by the evolution of distribution function $C_{i}$ on the Cartesian grids with selective velocity $\boldsymbol{e}_{i}$,

$$
C_{i}\left(x+c e_{i} \Delta t, t+\Delta t\right)-C_{i}(x, t)=\Psi_{i}(C) \quad i=0,1, \ldots, 4
$$

where $c$ denotes the velocity, $\Delta t$ is the time step, and $\Psi_{i}(C)$ is the discrete collision operator, which is given by,

$$
\begin{gathered}
\Psi_{i}(C)=-\frac{1}{\tau_{c}}\left[C_{i}(x, t)-C_{i}^{e q}(x, t)\right]+\Delta t \frac{R}{4} \\
\tau_{c}=2 \Delta t D / \Delta x^{2}+0.5
\end{gathered}
$$

in which $R$ is the source item, $C_{i}^{e q}$ is the equilibrium distribution function of the methane concentration, and depends on the velocity $u$, temperature $T$ of the gas, which is typically defined as

$$
C_{i}^{e q}(x, t)=\frac{C(x, t)}{4}\left[1+2 \frac{\boldsymbol{e}_{j} \boldsymbol{u}}{c_{s}^{2}}\right], \quad i=0,1, \ldots, 4,
$$


$\tau_{c}$ is the relaxation factor, $D$ is the methane gas diffusion coefficient, $c_{S}$ and $\Delta x$ is the same as mentioned above, the direction set is defined as

$$
\boldsymbol{e}_{i}=\left[\begin{array}{cccc}
1 & 0 & -1 & 0 \\
0 & 1 & 0 & -1
\end{array}\right]
$$

$C(x, t)$ is the methane concentration in lattice $x$ at time $t$, which is calculated by

$$
C=\sum_{i=1}^{4} C_{i}(x, t)
$$

This model can also deduce the macroscopic equations for gas concentration diffusion.

$$
\frac{\partial C}{\partial t}=-\nabla \cdot(u C)+D \nabla^{2} C+R
$$

The Boussinesq approximation method is employed to implement the coupling mode of the airflow velocity and the methane concentration field; the evolution equation after coupling is

$$
\begin{gathered}
f_{i}\left(x+c e_{i} \Delta t, t+\Delta t\right)-f_{i}(x, t)=-\frac{1}{\tau}\left[f_{i}(x, t)-f_{i}^{e q}(x, t)\right]+g_{i} \\
g_{i}=\frac{k_{i}}{2} e_{i} g \beta_{s}\left(C-C_{0}\right)
\end{gathered}
$$

where $g_{i}, k_{i}$ and $C_{0}$ are the gravitational acceleration, the volume expansion coefficient of concentration and reference concentration constant respectively.

\subsubsection{The Turbulence Model}

Airflow behavior in underground coal mine laneway is generally turbulent, hence our flow solver based on LBM should take the effect of turbulence into account. Therefore, a wide range of scales of fluid motion existed in the coupling flow of the air and methane concentration is necessary to resolve. The simulation in all scales in a turbulence flow requires a very fine lattice and long computation time. Instead, a Smagorinsky sub-lattice model is utilized to simulate the effects of the unresolved sub-lattice motion on the resolved motion, which is similar to the large eddy simulation (LES) in traditional CFD methods [44]. As for the LBM evolution equation, the effect of the sub-lattice can be addressed by local relaxation time [45-47]. Then the modified relaxation time is adopted in the relaxation process, and every node of lattice would relax at different rates.

\subsection{Implementation of the LBM Integrated with LrGIS Platform}

Numerical model and GIS integration can be achieved using one of the three potential coupling strategies outlined in Table 1 [28]. Here, a tight coupling approach is used to integrate LBM in LrGIS platform, which requires a straightforward connection from the geometric laneway data to LBM based numerical model. An applicable numerical coupling model was developed, which was specifically designed to adapt geometric laneway data to be integrated with LrGIS platform. The implementation procedure focuses on improving the geometry of the input features that configure the model geometry, the boundary conditions, and other aspects of spatiotemporal modeling, which avoids explicit mesh generation procedure that is necessary in traditional CFD method. It will help modelers in the development of future projects. 
Table 1. Characteristics of different strategies for GIS and model integration.

\begin{tabular}{|c|c|c|c|}
\hline \multirow{2}{*}{ Characteristics } & \multicolumn{3}{|c|}{ Coupling Type } \\
\hline & Loose & Tight & Embedded \\
\hline Shared data and method base & & $\sqrt{ }$ & $\sqrt{ }$ \\
\hline Intra-simulation query and control & & & $\sqrt{ }$ \\
\hline Advantages \& disadvantages & $\begin{array}{l}\text { Different GIS and Modeling } \\
\text { packages have independent } \\
\text { interfaces. Information sharing is } \\
\text { based on exchange of files, } \\
\text { which can be error prone } \\
\text { and inefficient. Different tools } \\
\text { and libraries facilitate } \\
\text { independent development. }\end{array}$ & $\begin{array}{l}\text { The coupled platform merges } \\
\text { different modules in a single } \\
\text { powerful system, which avoids } \\
\text { inconsistency and data loss } \\
\text { originating from redundancy } \\
\text { and heterogeneity of method base. } \\
\text { Data exchange is automatic } \\
\text { between GIS platform and model. }\end{array}$ & $\begin{array}{l}\text { Programming and data management } \\
\text { is significantly complex, and the code } \\
\text { base is not easy to be changed due to } \\
\text { embedded large source code structure. } \\
\text { Steerable simulation according to } \\
\text { the changes of parameters } \\
\text { or processes. }\end{array}$ \\
\hline Examples & [48] & [49] & [50] \\
\hline
\end{tabular}

Figure 3 shows the entire architecture of numerical model integrated with LrGIS platform. The platform consists of three layers: Data source, GIS kernel, and desktop application. Different kinds of data source can be quickly stored, retrieved, indexed, and searched by SDE interface layer. GeoLattice can be constructed on LrGIS platform to prepare for the numerical simulation, like other geometric models such as GeoPoint, GeoLine. In terms of the data management, LrGIS contains many entity models, such as GeoEntity, RasterEntity. Similarly, FluentEntity is specifically designed to manage the field data obtained by fluid simulation. The physical attributes consist of velocity, pressure, temperature, gas concentration, and display attributes comprise geometrical shape, color rendering, profile. The simulated result can be visualized on LrGIS GUI and execute the spatial query function. Specifically, two main parts have been solved: (i) GeoLattice and FluentEntity setup, which constructs the laneway model and configures the geometry and attributes of each lattice to make them valid for numerical computation; (ii) Database organization, which controls and traces the output data that are obtained from the numerical simulation. The data is saved as time series grid table files, which can be called by FluentEntity.

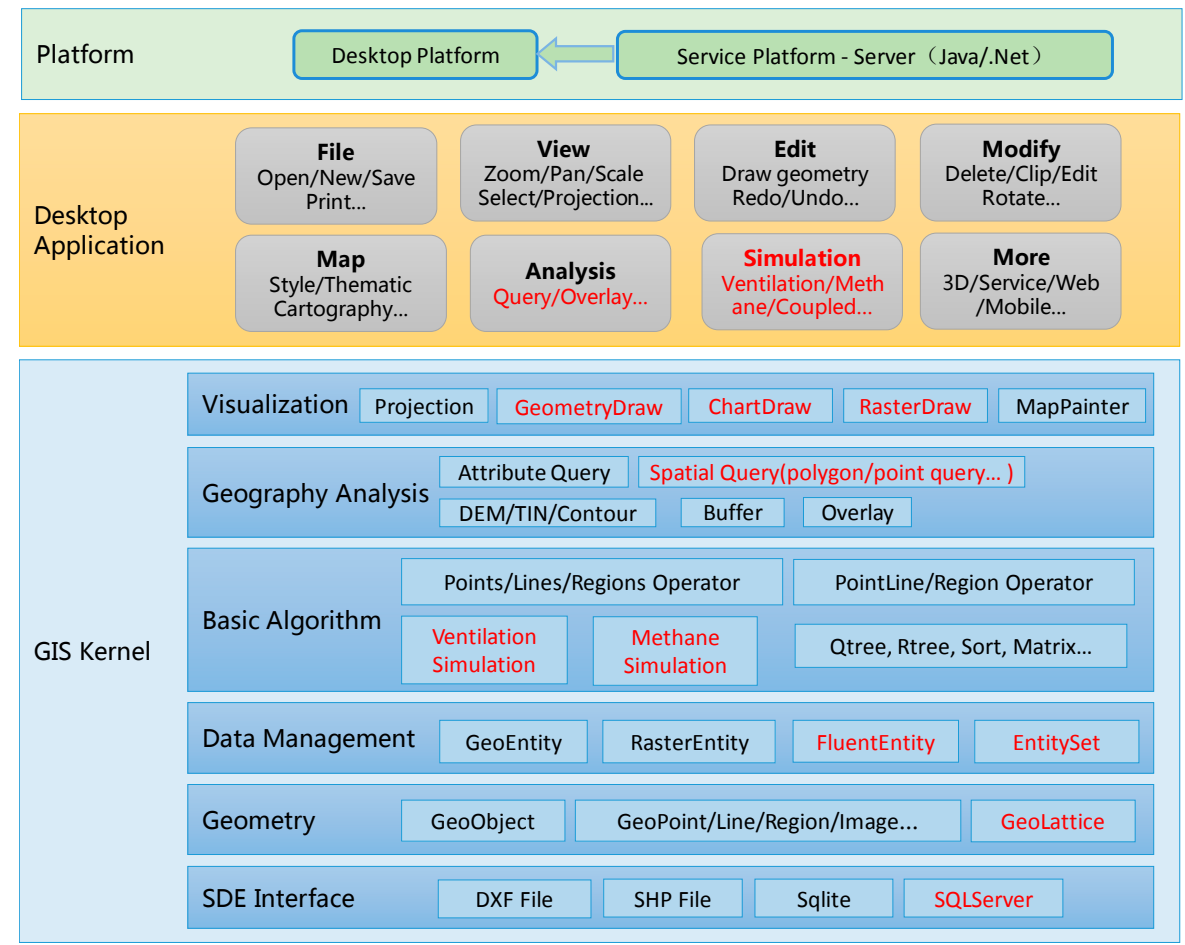

\begin{tabular}{|l|l|l|l|}
\hline Data Source & Vector file & Raster file & Database \\
\hline
\end{tabular}

Figure 3. The entire architecture of numerical model on LrGIS platform. 
The lattice attributes and the corresponding boundary conditions are described in details: different kinds of lattice nodes on the geometry are associated with different material numbers in their own coordinates. Figure 4 presents a 2D top view of the laneway, with material number one, two, three, four and five corresponding to fluid region, inflow, outflow, methane mass flow, and bounce back boundary, respectively. Then different material numbers are defined with the corresponding dynamic conditions, which are described, as follows:

(i) fluid region: all species can move in this area, namely, the mesoscopic streaming and collision step of particles happened;

(ii) inflow: the velocity inflow boundary condition is adopted, which means that the airflow is through this boundary with specified velocity;

(iii) outflow: the outlet of the laneway is set to be under the constant pressure boundary condition;

(iv) methane mass flow: the methane gas is released evenly from working face area with a total flow rate of $0.2 \mathrm{~m}^{3} / \mathrm{s}$;

(v) bounced back boundary: the no-slip boundary is prescribed at all laneway walls.

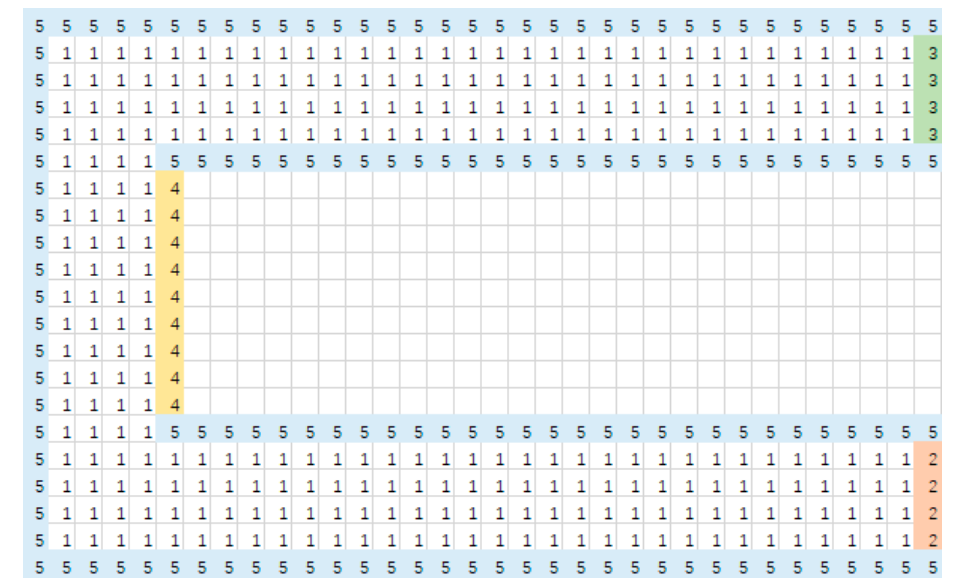

Figure 4. 2D top view of the laneway with associated material numbers.

The detailed algorithm of LBM based numerical model integrated with LongRuanGIS platform is implemented as follows (Table 2), where the computational complexity of this numerical model is the product of lattice amount and number of iterations. 
Table 2. Algorithm steps of the numerical model.

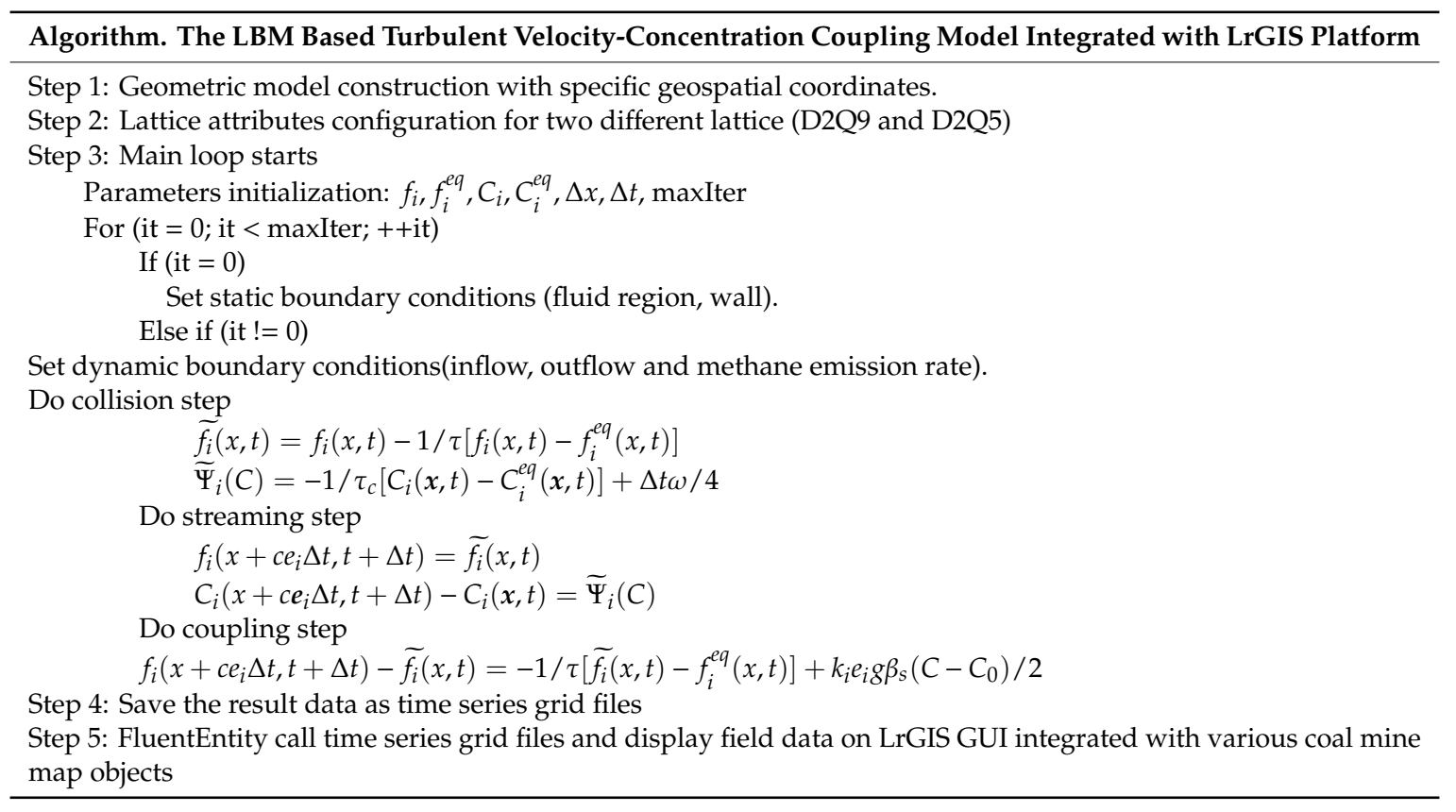

\section{Simulation and Integration Results}

\subsection{Spatiotemporal Characteristics of Airflow and Methane Distribution}

The established model was numerically simulated and all terms of the evolution equations, including streaming step and collision step were solved. The coupling mode is solved using Boussinesq approximation method. The detailed parameters are presented in Table 3. The simulation required around $1.6 \mathrm{~h}$ on workstations with four core processors and 8 GB RAM.

Table 3. Parameters for LBM simulation.

\begin{tabular}{cc}
\hline Parameters & Setting \\
\hline Air density $\left(\mathrm{kg} / \mathrm{m}^{3}\right)$ & 1.225 \\
Methane gas density $\left(\mathrm{kg} / \mathrm{m}^{3}\right)$ & 0.716 \\
Turbulent viscosity $\left(\mathrm{m}^{2} / \mathrm{s}\right)$ & $1.7894 \times 10^{-5}$ \\
Turbulent kinetic energy & 1.3 \\
Convergence criteria & $10 \mathrm{e}^{-6}$ \\
Calculation steps & 10000 \\
Lattice size $(\mathrm{m})$ & 0.1 \\
Time step size $(\mathrm{s})$ & 1 \\
Renolds number & 500 \\
Initial pressure & $1 / 3$ \\
Air velocity of inlet $(\mathrm{m} / \mathrm{s})$ & 3.17 \\
Methane volume flow at the working face $\left(\mathrm{m}^{3} / \mathrm{s}\right)$ & 0.2 \\
\hline
\end{tabular}

The velocity field of airflow is one of the main factors which directly influence the methane distribution and mitigation. As presented in Figures 5 and 6, the predicted air velocity and methane concentration profiles were investigated at different time points with a fixed methane emission rate of $0.2 \mathrm{~m}^{3} / \mathrm{s}$. Here, we analysed the overall spatiotemporal characteristics of velocity behaviour and methane distribution inside the laneway. The pressing air is flowing from the intake side of the laneway at high velocity, and there exists an obvious jet flow, which goes along the laneway and flows into the working face. When the airflow arrives at the working face, it is obstructed by the face and the airflow changes its flow direction and flows along the working face area, as can be 
seen in Figure 5a-c about the airflow distribution at different times. Correspondingly, the methane gas gushes from the coal seam and disperses into the working face with the impact of airflow after about $5 \mathrm{~min}$. (Figure 6a), when the airflow is distributed fully in the working face area. Then the methane gas gradually diluted and decreased to a low concentration level with the effect of airflow in the wind outtake side of the laneway and approximately becomes stable at $10 \mathrm{~min}$. (Figure $6 \mathrm{~b}-\mathrm{d}$ ).
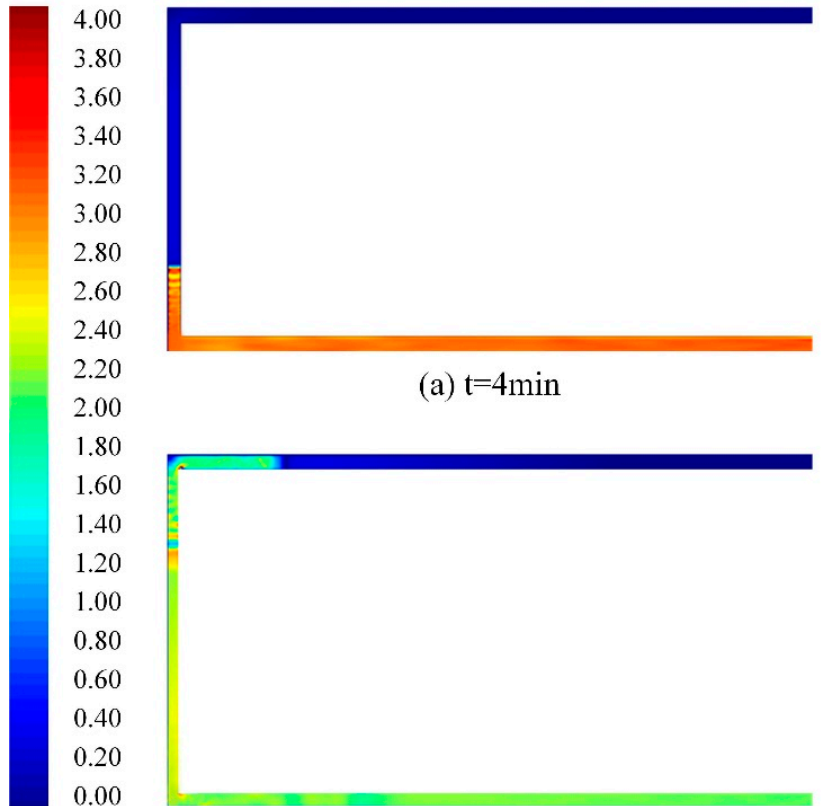

(a) $\mathrm{t}=4 \mathrm{~min}$

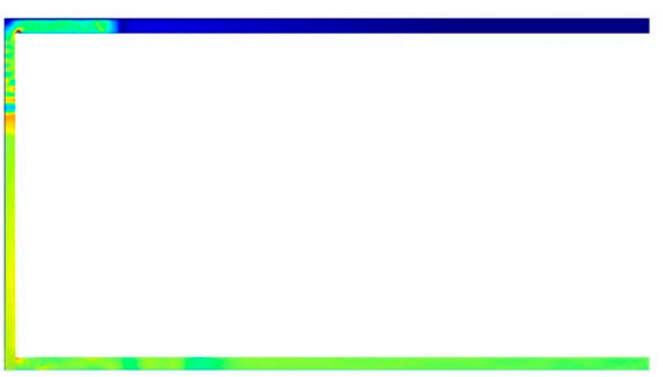

(c) $\mathrm{t}=5.5 \mathrm{~min}$

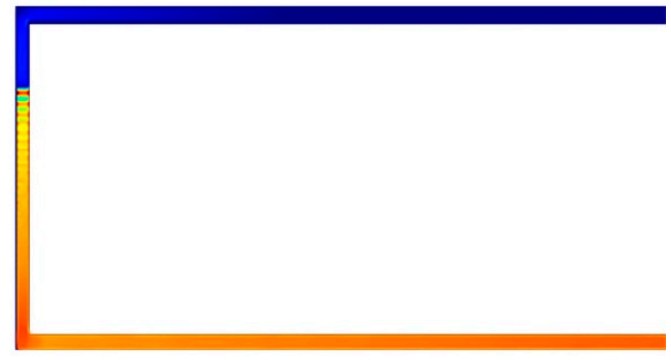

(b) $\mathrm{t}=4.5 \mathrm{~min}$

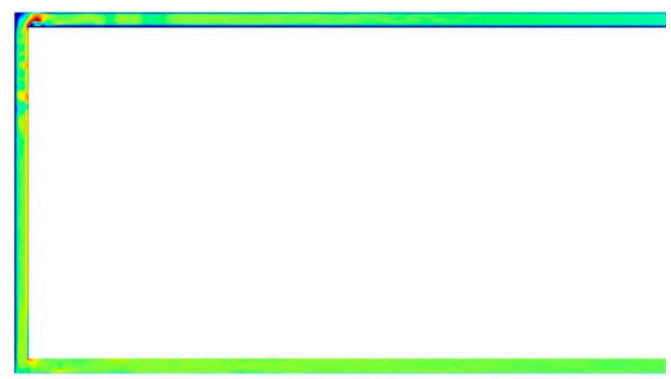

(d) $\mathrm{t}=7.5 \mathrm{~min}$

Figure 5. Airflow velocity $(\mathrm{m} / \mathrm{s})$ profiles at different time points.

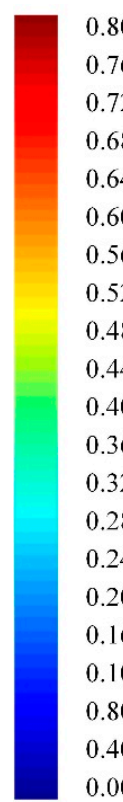

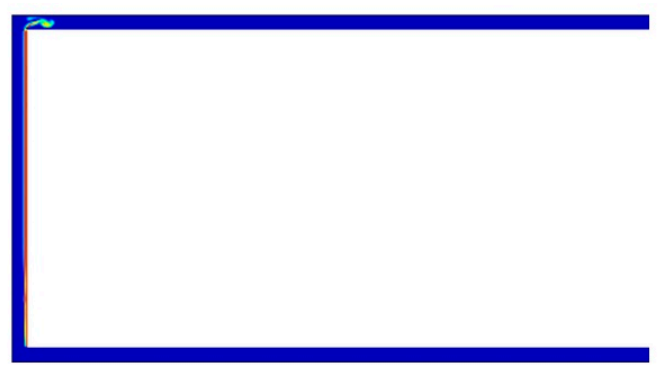

(a) $\mathrm{t}=5 \mathrm{~min}$

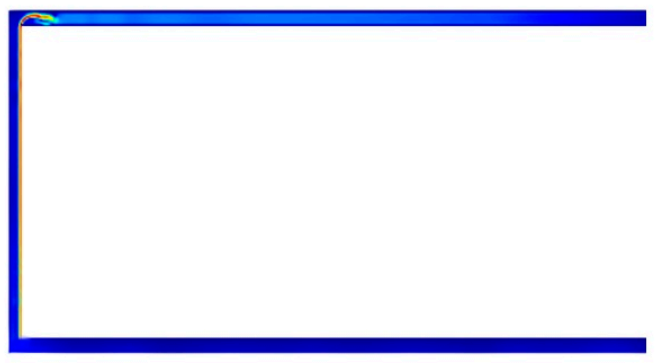

(c) $\mathrm{t}=7 \mathrm{~min}$

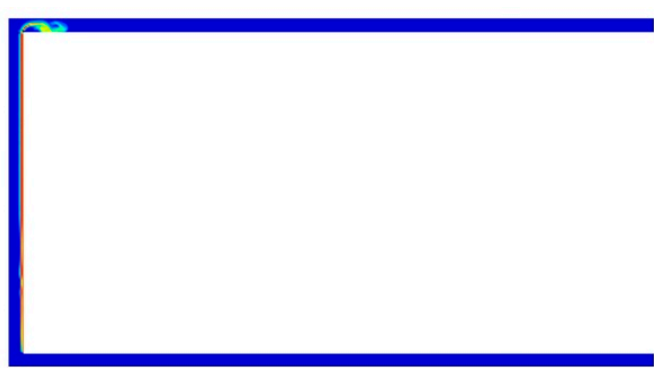

(b) $\mathrm{t}=5.5 \mathrm{~min}$

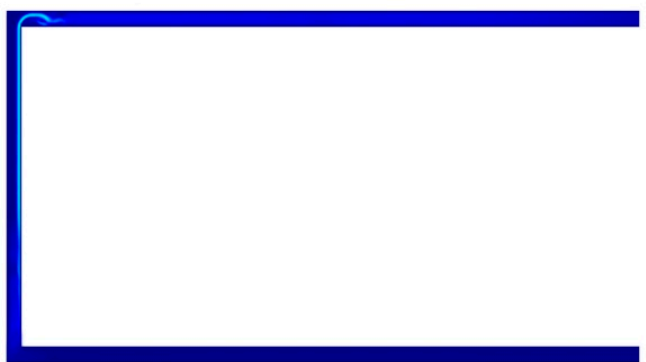

(d) $\mathrm{t}=10 \mathrm{~min}$

Figure 6. Methane concentration $(v / v \%)$ profiles at different time points.

\subsection{The Spatiotemporal Analysis of Methane Concentration Based on LrGIS}

Based on the proposed integration method, the CFD simulation function is developed on LrGIS platform, which supports the numerical simulation and can display the simulated data on 
the ventilation system map on the basis of coordinate matching, and also facilitate the visualization of additional relevant data. The effective user access, the location-based information, and means of viewing and analyzing for the simulated data are also the main focuses. Thus, the numerical model is integrated with LrGIS platform, of which the query and analysis functions can also be operated based on the numerical simulation results. Figure 7 shows the map of ventilation system of $5 \#$ Sijiazhuang coal mine, the study area of 15116 working face in this case is located in the bottom right corner on the map, with the latitude and longitude ranging from 105,800 to $106,020 \mathrm{~m}$ and from 67,125 to $67,725 \mathrm{~m}$. The roam and move functions allow users to observe more detailed features on the coal mine map.

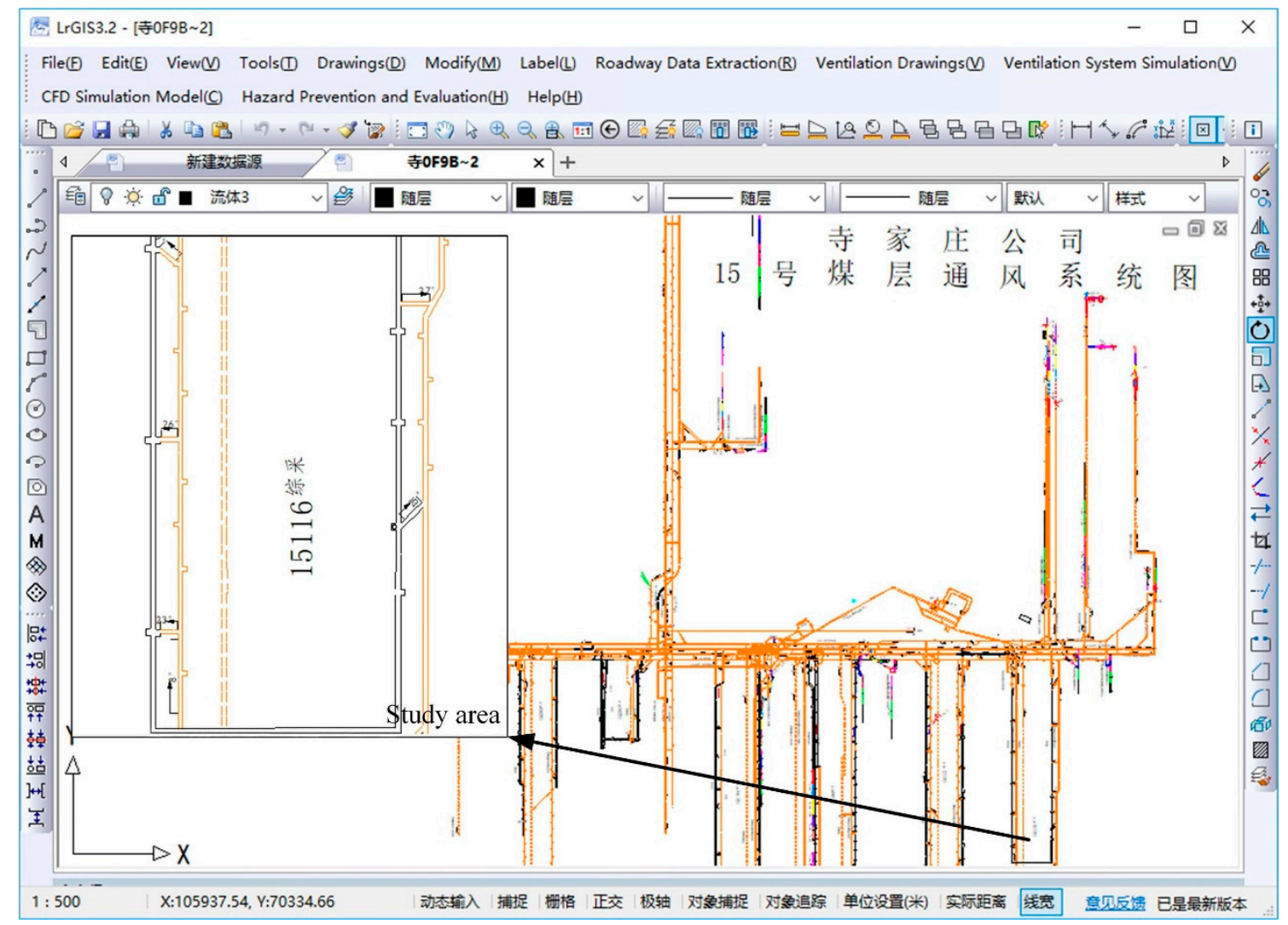

Figure 7. Study area of the ventilation system map in 15\# Sijiazhuang coal mine.

To demonstrate the applicability of the CFD simulation function in LrGIS platform, the spatiotemporal analysis for our case study is performed. First, based on the specified numerical parameters, the geometry is prepared and lattice is generated, which are then used to perform the numerical simulating procedure. It is noted that the properties of lattices include the lattice ID, material numbers, and the coordinates. The output data of the simulation is saved as a series of time ordered text files, which contains the $X, Y$ coordinates, the airflow velocity, and methane concentration of each lattice. The tool of methane emission analysis in the CFD simulation model allows for us to demonstrate the spatiotemporal distribution of the airflow behavior and methane concentration. By specifying the time point, the corresponding spatiotemporal distribution of the methane concentration can be visualized on the ventilation system map, together with various spatial coal mine layers, including geographical locations of fans, methane sensors and first aid stations, contour line, measured faultage, river and railway, and also the fictitious graticule, as presented in Figure 8. These information provide managers and miners the access to the large quantities of geographic field data, as well as its query and analysis for the location-based information integrated with simulated data.

Basically, the managers or decision makers can use the program to perform several queries according to the specifications, such as, (i) basic mine mapping operations integrated with simulated 
field data, (ii) finding operation, and (iii) location-based information operation. For example, the maximum methane concentration with its coordinates in an area of interest will be demonstrated immediately by the function of polygonal query, which also shows whether the predicted concentration exceeds the threshold value, as can be seen in Figure 9.

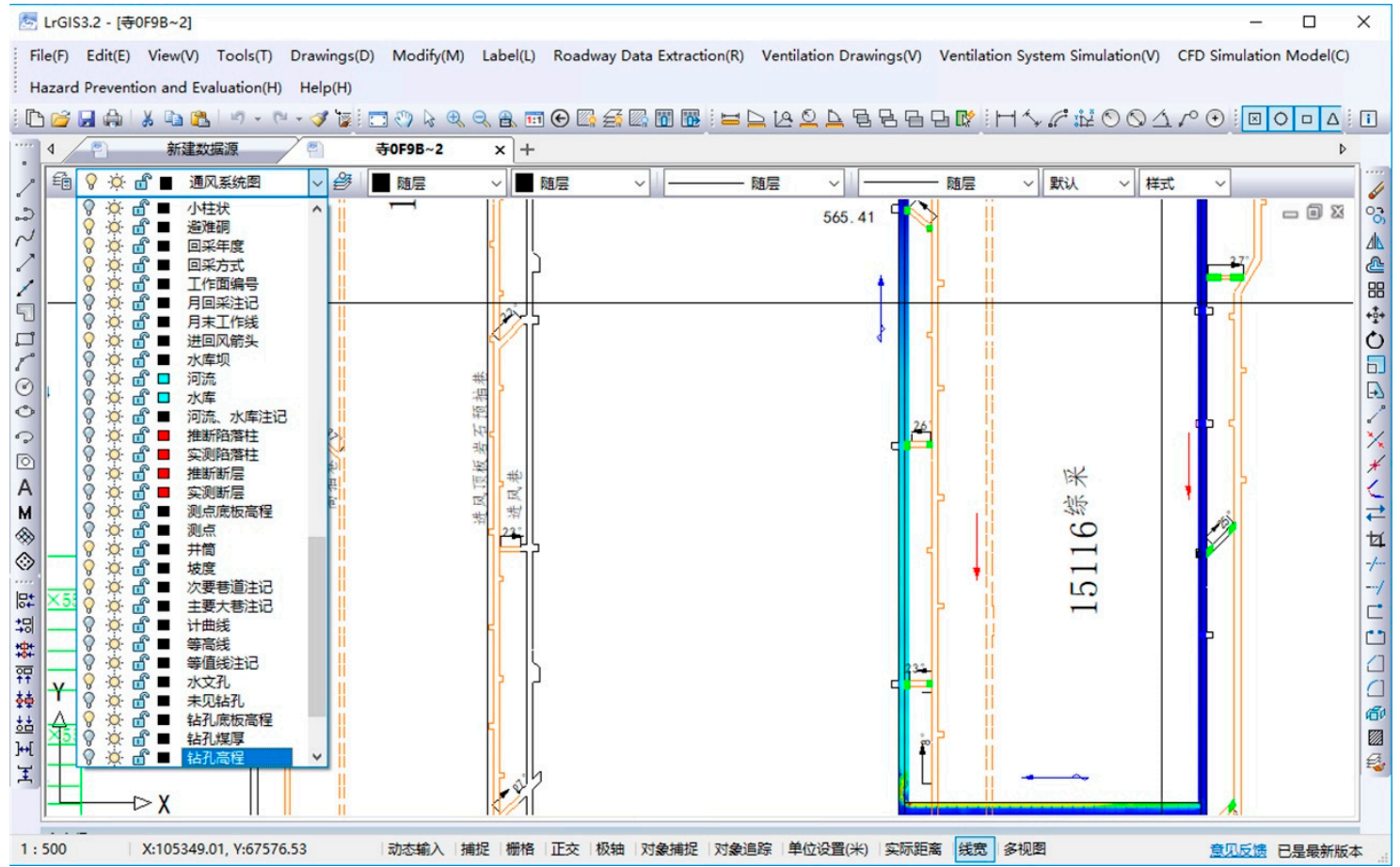

Figure 8. Methane concentration integrated with various spatial coal mine layers.

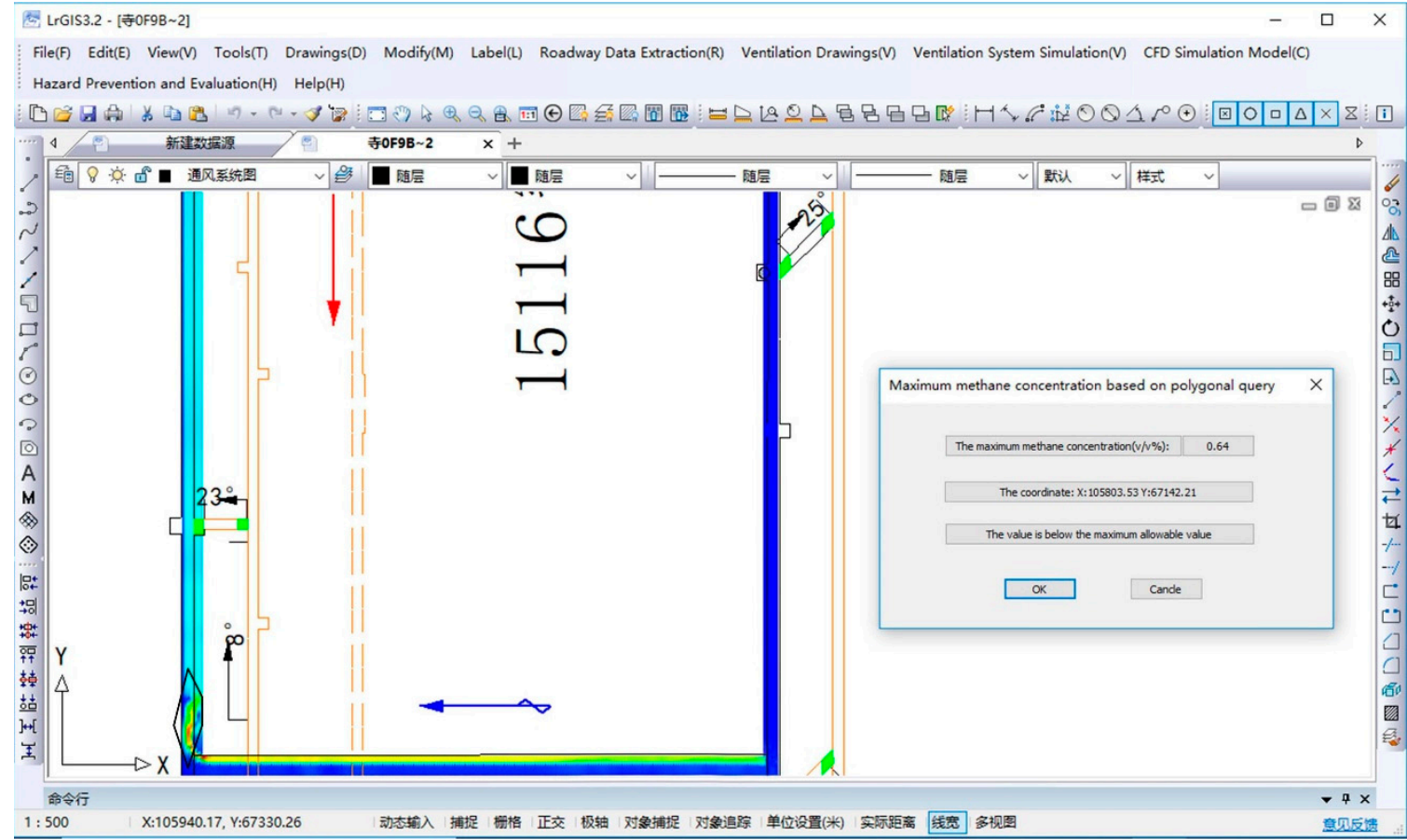

Figure 9. Methane concentration visualization and polygonal query analysis.

Besides, if a specific point is of interest in an actual field, for example, the position is where miners always work, then the point can be clicked or the coordinate can be input on the interface 
to get the methane concentration curve changed over time, which will be displayed on the interface and provides intuitive information for the dynamic regularity of methane concentration. The time series data can also be validated with monitored data based on the database management system. Here, one of the methane sensors located $10 \mathrm{~m}$ away from the working face in the outtake side of the laneway is selected to perform the data validation with the monitored data, as presented in Figure 10. The numerical simulation shows that, after the algorithm converges in $10 \mathrm{~min}$, and the airflow distributes fully and stably within the laneway. The simulated methane concentration maintains at a stable level and agrees well with the monitored data after $10 \mathrm{~min}$. Thus, some detailed information can be provided for decision makers, such as how long the methane distribution will be stable with the effect of the ventilation system, the peak value of methane concentration, and its specific position, which can guide miners about when to avoid the methane accident if the value is beyond the maximum allowable value. Besides, the methane distribution can also guide the production intensity, and reasonable arrangement of underground coal mine equipment.

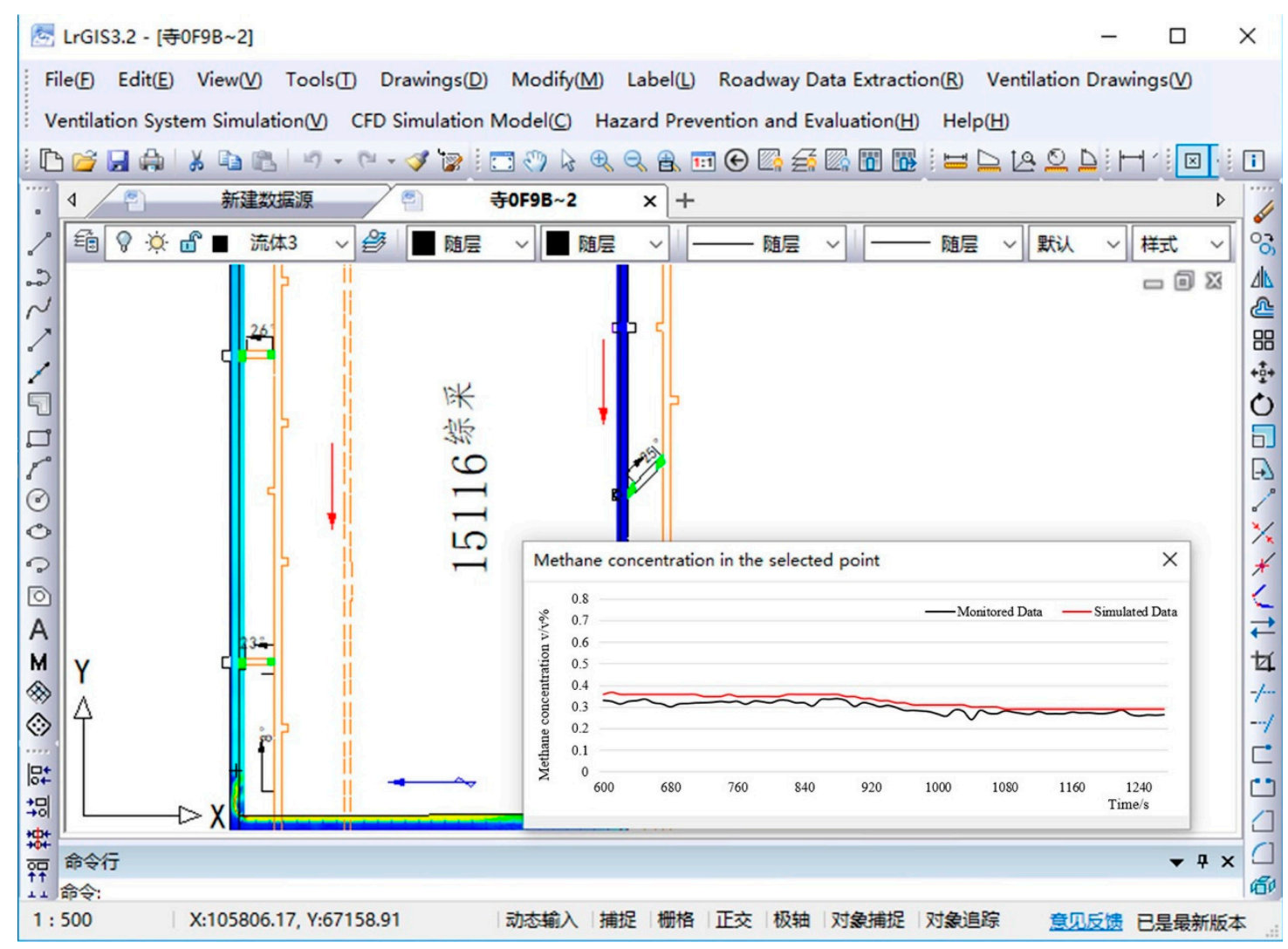

Figure 10. Point query analysis and data validation.

\subsection{The Comprehensive Comparison of Traditional CFD Method and LBM}

According to the kinetic theory [40], both traditional CFD method and LBM can satisfy the macroscopic Navier-Stokes equation in their continuous forms. However, Navier-Stokes equations are the target for LBM while the starting point for the traditional CFD methods, and these two methods also differ, not only in the spatial discretization forms, but also in the temporal discretization forms. Although a number of studies have been conducted to comprehensively compare their difference in essence, there is still a lack of comparison based on the actual simulation example. In this case study, comprehensive comparison and analysis between the proposed turbulent LBM based velocity-concentration coupling model and traditional CFD method are conducted from the following three aspects: accuracy, simulation efficiency, simplicity, and advantages of the integration with LrGIS platform. 
Here, the traditional CFD method was implemented based on Computational Fluid Dynamics platform (Fluent) by employing the Euler-Lagrange model, all terms of the governing equations and constitutive relations were solved with the semi-implicit pressure-linked equation (SIMPLE) algorithm and second-order upwind scheme. The turbulence model and boundary conditions were solved using finite volume solver. The dynamic boundary parameters are the same with the LBM. Here, a line at $3 \mathrm{~m}$ high in the middle of the outtake side of laneway was chosen to investigate the airflow velocity and methane concentration at two different time points. As can be seen in Figures 11 and 12, it shows that both methods agree well with each other in the overall tendency of airflow velocity and methane concentration.

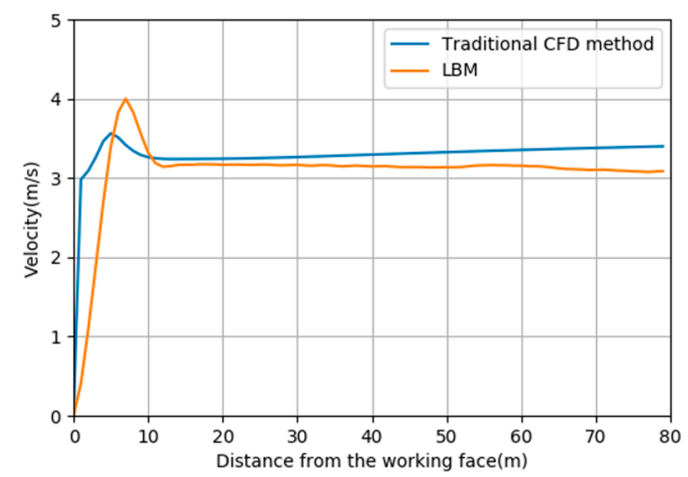

(a) Airflow velocity at $10 \mathrm{~min}$.

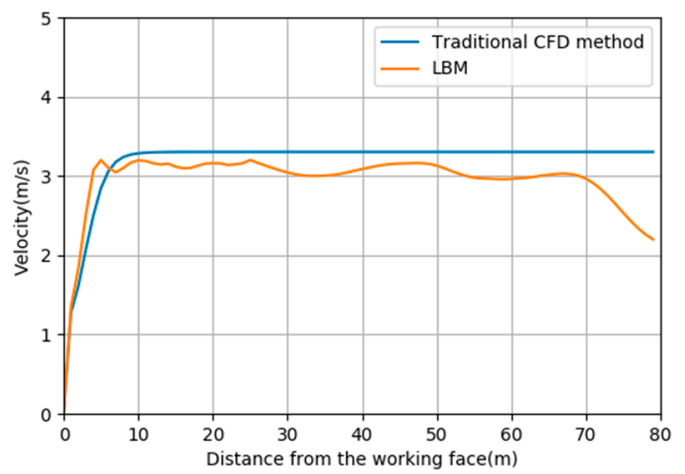

(b) Airflow velocity at 15 min.

Figure 11. Airflow velocity at the selected line.

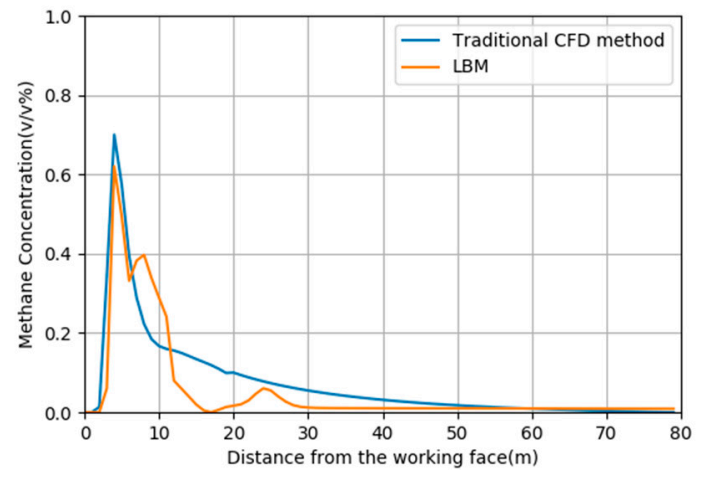

(a) Methane concentration at $10 \mathrm{~min}$.

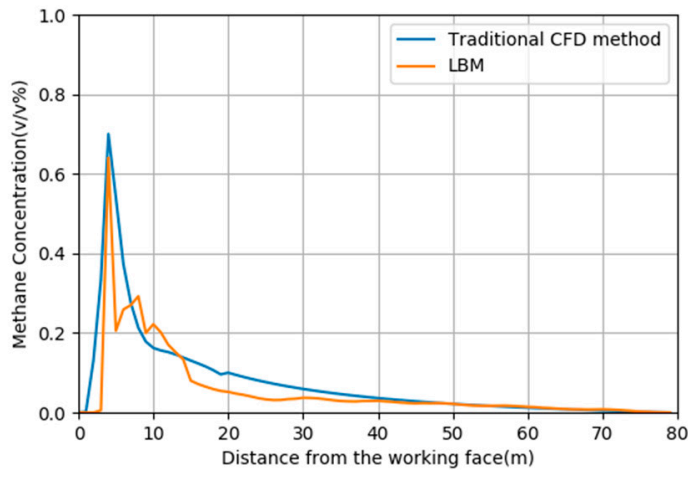

(b) Methane concentration at $15 \mathrm{~min}$.

Figure 12. Methane concentration at the selected line.

The traditional CFD simulation requires about $20 \mathrm{~min}$ on computers with four core processors and $8 \mathrm{~GB}$ RAM, while the model adopted in this paper uses around $15 \mathrm{~min}$. It is noted that Fluent belongs to the third-party professional fluid dynamics simulation software, its independent geometric modeling and numerical simulation process makes it significantly difficult to directly guide the on-site problems, and the required data have to be preset and saved manually in the early stage of the simulation, which shows the poor practicability when applied in the on-site guidance. However, in this paper, the property of the unnecessary explicit mesh generation and the inherent simplicity of the algorithm make LBM more efficient and easy to integrate with the LrGIS platform. Specifically, the integrated system essentially implemented four objectives: (i) enabling managers to simulate case study directly on the GIS system and visualize the simulated results intuitively; (ii) storing the simulated spatiotemporal field data in the database system, which can be used for post analysis; (iii) demonstrating the simulated field data with various coal mine map objects, and providing miners the spatiotemporal analyze and query operation tools to obtain the useful location-based information; (iv) validating the results based on the coal mine monitoring system of Sijiazhuang coal mine. Therefore, by utilizing the synergies between GISs and spatiotemporal modeling, the integrated system is effective in providing decision 
supports for safety production, which is expected to improve the health standards in the underground coal mines.

The comparison case study demonstrates that the model and integration mode carried out in this study is more efficient in improving the computational efficiency and simplifying the integration mode of numerical simulation model with the GIS platform. It can also be concluded that the integrated system is more practical in on-site application compared with numerical simulation software.

\section{Conclusions}

Due to the lack of an effective platform for the practical application of numerical simulation methods in the underground coal mine systems, the concept of tight coupling of GIS and spatiotemporal modeling is introduced in this area for the first time.

Specifically, a turbulent LBM based velocity-concentration coupling model is proposed and tightly integrated with LrGIS platform by developing the FluentEntity model, which allows mine managers to simulate ventilation-related case study directly on the LrGIS system, visualize the simulated field data on the ventilation system map and other coal mine layers intuitively, and operate the spatiotemporal analyze and query to get location-based information, and therefore to guide the practical operation. Besides, the simulated result is validated with monitored data of Sijiazhuang underground coal mine, which shows the accuracy and reliability of the proposed model. In addition, by comparing with the traditional CFD method, the developed coupling scheme is demonstrated to be more efficient and easy to be integrated with GIS system.

In conclusion, this study provides a possibility to integrate the numerical simulation model with the GIS platform effectively, and shows that GIS could not only serve to carry out general constructive safety, but also generate case scenarios, quantify spatiotemporal processes, and therefore improve the safety standards for coal mines by GIS-coupled spatiotemporal modeling, analysis, and query tools. Furthermore, the system is more flexible and potentially applicable to other case study, like ventilation network solution, including both local network and the whole mine ventilation system.

Author Contributions: During this study, H.L. designed and performed the numerical simulation, and wrote the paper, S.M. and M.L. contributed materials, S.W. integrated the numerical model with the LrGIS platform.

Funding: This work is financially supported by the National Key Research and Development Program of China: [Grant Number 2016YFC0803108].

Acknowledgments: The authors would like to thank the anonymous reviewers who contributed to the quality of this letter by providing helpful suggestions.

Conflicts of Interest: No potential conflict of interest was reported by the authors.

\section{References}

1. Nakayama, S.; Kim, Y.K.; Jo, Y.D. Simulation of methane gas distribution by computational fluid dynamics. In Mining and Science Technology; Xie, H.P., Golosinski, T.S., Eds.; Balkema Publisher: Brookfield, VT, USA, 1999; pp. 259-262.

2. Kurnia, J.C.; Sasmito, A.P.; Wong, W.Y.; Mujumdar, A.S. Prediction and innovative control strategies for oxygen and hazardous gases from diesel emission in underground mines. Sci. Total Environ. 2014, 481, 317-334. [CrossRef]

3. Kurnia, J.C.; Xu, P.; Sasmito, A.P. A novel concept of enhanced gas recovery strategy from ventilation air methane in underground coal mines-A computational investigation. J. Nat. Gas Sci. Eng. 2016, 35, 661-672. [CrossRef]

4. Liu, H.; Wu, X.; Mao, S.; Li, M.; Yue, J. A Time Varying Ventilation and Dust Control Strategy Based on the Temporospatial Characteristics of Dust Dispersion. Minerals 2017, 7, 59. [CrossRef]

5. Xu, G.; Luxbacher, K.D.; Ragab, S.; Xu, J.; Ding, X. Computational fluid dynamics applied to mining engineering: A review. Int. J. Min. Reclam. Environ. 2017, 31, 251-275. [CrossRef]

6. Sun, Z.; Mao, S.; Wu, C. Assistant Decision System of Gas Explosion Emergency Rescue Based on Monitoring Data and CFD. Saf. Coal Mines 2016, 47, 83-86. [CrossRef] 
7. Zhu, C.; Lin, B.; Ye, Q.; Zhai, C. Effect of roadway turnings on gas explosion propagation characteristics in coal mines. Min. Sci. Technol. 2011, 21, 365-369. [CrossRef]

8. Tian, Z.; Liang, Z.; Niu, Y.; Li, C.; Tu, X.; Fan, D. Simulation of the methane emission in rice fields in China during the past 40 years by DNDC model and GIS technical. In Proceedings of the 2014 Third International Conference on Agro-Geoinformatics, Beijing, China, 11-14 August 2014.

9. Goodchild, M.F.; Haining, R.; Wise, S. Integrating GIS and spatial data analysis: Problem and possibilities. Int. J. Geogr. Inf. Syst. 1992, 6, 407-423. [CrossRef]

10. Duffy, C.; Leonard, L.; Bhatt, G.; Yu, X.; Giles, L. Watershed Reanalysis: Towards a National Strategy for Model-Data Integration. In Proceedings of the 2011 IEEE Seventh International Conference on e-Science Workshops (eScienceW 2011), Stockholm, Sweden, 5-8 December 2011; pp. 61-65.

11. Juanle, W.; Kan, W.; Kuan, W. Integrated GIS solution to mining subsidence assistant decision in mining area. In Proceedings of the IGARSS 2004, 2004 IEEE International Geoscience and Remote Sensing Symposium, Anchorage, AK, USA, 20-24 September 2004; pp. 2868-2871.

12. Kolli, S.S.; Damodaran, P.S.; Evans, G.W. Geographic Information System Based Decision Support Systems for Facility Location, Routing and Scheduling. Comput. Ind. Eng. 1993, 25, 369-372. [CrossRef]

13. Banerjee, T.K. A GIS Solution for an Integrated Underground Coal Mine Management: A Conceptual Platform. J. Manag. Policies Pract. 2014, 2, 129-143.

14. Şalap, S.; Karslığlu, M.O.; Demirel, N.; Karslioglu, M.O. Development of a GIS-based monitoring and management system for underground coal mining safety. Int. J. Coal Geol. 2009, 80, 105-112. [CrossRef]

15. Suh, J.; Kim, S.-M.; Yi, H.; Choi, Y. An Overview of GIS-Based Modeling and Assessment of Mining-Induced Hazards: Soil, Water, and Forest. Int. J. Environ. Res. Public Health 2017, 14, 1463. [CrossRef]

16. Yenilmez, F.; Kuter, N.; Emil, M.K.; Aksoy, A. Evaluation of pollution levels at an abandoned coal mine site in Turkey with the aid of GIS. Int. J. Coal Geol. 2011, 86, 12-19. [CrossRef]

17. Ni, X.-M.; Chen, P.; Guo, L. Development of a decision-making system for coalbed methane development based on GIS. In Proceedings of the 2010 2nd Conference on Environmental Science and Information Application Technology, ESIAT 2010, Wuhan, China, 17-18 July 2010; pp. 348-351.

18. Yao, Y.; Liu, D.; Tang, D.; Huang, W.; Tang, S. Evaluation of the Coalbed Methane Potential by a GIS-Based Fuzzy AHP Model. In Proceedings of the 2009 Sixth International Conference on Fuzzy Systems and Knowledge Discovery, Tianjin, China, 14-16 August 2009; pp. 281-285.

19. Fang, K. GIS network analysis in rescue of coal mine. In Proceedings of the 21st International Society for Photogrammetry and Remote Sensing (ISPRS) Congress, Beijing, China, 3-11 July 2008.

20. Van Dijk, P.M.; Wang, H.Y.; Van Genderen, J.L. Earth observation knowledge transfer: The example of ITC's coal fire project. In Proceedings of the 20th International Society for Photogrammetry and Remote Sensing (ISPRS) Congress, Istanbul, Turkey, 12-23 July 2004.

21. Kresic, N.; Mikszewski, A. Hydrogeological Conceptual Site Models: Data Analysis and Visualization. 2012. Available online: https://books.google.com/books?id=6H383WiTiSQC\&pgis=1 (accessed on 10 May 2019).

22. Ahm, Z.; Ashraf, A. Integration of Groundwater Flow Modeling and GIS. In Water Resources Management and Modeling; Nayak, P., Ed.; InTech: Rijeka, Croatia, 2012; pp. 239-262.

23. Li, M.; Liu, H.; Yang, C. A Real-Time GIS Platform for High Sour Gas Leakage Simulation, Evaluation and Visualization. ISPRS Ann. Photogramm. Remote Sens. Spat. Inf. Sci. 2015, 2, 225-231. [CrossRef]

24. Liu, Z.-P.; Liu, J.; He, Y.-w. Seamless coupling of 3D GIS techniques with FEM and its application to tunneling engineering. Rock Soil Mech. 2017, 38, 865-874. [CrossRef]

25. Zheng, M.; Jin, M. Modeling and Simulation of Toxic Gas Dispersion in Urban Street Supported by GIS. Geomat. Inf. Sci. Wuhan Univ. 2013, 38, 935-939.

26. Ma, J.T.; Chen, S.Z.; Zhu, X.T.; He, Z.C. Finite element numerical simulation method of groundwater flow and its application under 3D GIS. J. Geo-inf. Sci. 2016, 18, 749-757. [CrossRef]

27. Alcaraz, M.; Vázquez-Suñé, E.; Velasco, V.; Criollo, R. A loosely coupled GIS and hydrogeological modeling framework. Environ. Earth Sci. 2017, 76, 1-13. [CrossRef]

28. Bhatt, G.; Kumar, M.; Duffy, C.J. A tightly coupled GIS and distributed hydrologic modeling framework. Environ. Model. Softw. 2014, 62, 70-84. [CrossRef]

29. Gebbert, S.; Pebesma, E. A temporal GIS for field based environmental modeling. Environ. Model. Softw. 2014, 53, 1-12. [CrossRef] 
30. Bai, L.; Yan, L.; Ma, Z. Interpolation and Prediction of Spatiotemporal Data Based on XML Integrated with Grey Dynamic Model. ISPRS Int. J. Geo-Inf. 2017, 6, 113. [CrossRef]

31. Papadimitriou, F. Modelling spatial landscape complexity using the Levenshtein algorithm. Ecol. Informat. 2009, 4, 48-55. [CrossRef]

32. Papadimitriou, F. The Algorithmic Complexity of Landscapes. Landsc. Res. 2012, 37, 591-611. [CrossRef]

33. He, X.; Doolen, G.D.; Clark, T. Comparison of the Lattice Boltzmann Method and the Artificial Compressibility Method for Navier-Stokes Equations. J. Comput. Phys. 2002, 179, 439-451. [CrossRef]

34. Khan, M.A.I.; Delbosc, N.; Noakes, C.J.; Summers, J. Real-time flow simulation of indoor environments using lattice Boltzmann method. Build. Simul. 2015, 8, 405-414. [CrossRef]

35. Perumal, D.A.; Dass, A.K. Simulation of incompressible flows in two-sided lid-driven square cavities. Part I-FDM. CFD Lett. 2010, 2, 13-24.

36. Chen, S.; Doolen, G.D. Lattice Boltzmann method for fluid flows. Annu. Rev. Fluid Mech. 1998, 30, $282-300$. [CrossRef]

37. Elhadidi, B.; Khalifa, H.E. Comparison of coarse grid lattice Boltzmann and Navier Stokes for real time flow simulations in rooms. Build. Simul. 2013, 6, 183-194. [CrossRef]

38. Heinzer, T.J.; Williams, M.D.; Dogrul, E.C.; Kadir, T.N.; Brush, C.F.; Chung, F.I. Implementation of a feature-constraint mesh generation algorithm within a GIS. Comput. Geosci. 2012, 49, 46-52. [CrossRef]

39. Lu, Q. 3D Simulation of Concentrative Emission Gas Spreading in Ventilation Networks Based on LBM. J. Syst. Simul. 2011, 23, 2384-2390. [CrossRef]

40. Li, M.; Zhang, X.-p.; Mao, S.-j. Study on deep mining safety control decision making system. The 6th International Conference on Mining Science \& Technology. Procedia Earth Planet. Sci. 2009, 1, 377-383. [CrossRef]

41. Lunarzewski, L.; Les, W. Gas emission prediction and recovery in underground coal mines. Int. J. Coal Geol. 1998, 35, 117-145. [CrossRef]

42. Bhatnagar, P.L.; Gross, E.P.; Krook, M. A Model for Collision Processes in Gases. I. Small Amplitude Processes in Charged and Neutral One-Component Systems. Phys. Rev. 1954, 94, 511-525. [CrossRef]

43. Guo, Z.; Shi, B.; Zheng, C. A coupled lattice BGK model for the Boussinesq equations. Int. J. Numer. Methods Fluids 2002, 39, 325-342. [CrossRef]

44. Smagorinsky, J. General Circulation Experiments with the Primitive Equations. Mon. Weather Rev. 1963, 91, 99-164. [CrossRef]

45. Hou, S.; Sterling, J.; Chen, S.; Doolen, G.D. A Lattice Boltzmann Subgrid Model for High Reynolds Number Flows. In Pattern Formation and Lattice gas Automata; Lawniczak, A.T., Kapral, R., Eds.; American Mathematical Society: Providence, RI, USA, 1996; pp. 151-166.

46. Zhang, S.J.; Lin, C.X. Application of Lattice Boltzmann Method in Indoor Airflow Simulation. HVACER Res. 2010, 16, 825-841.

47. Brimicombe, A. GIS Environmental Modelling and Engineering; Taylor \& Francis: London, UK, 2003; p. 320.

48. Hellweger, F.L.; Maidment, D.R. Definition and Connection of Hydrologic Elements using Geographic Data. J. Hydrol. Eng. 1999, 4, 10-18. [CrossRef]

49. Olivera, F.; Valenzuela, M.; Srinivasan, R.; Choi, J.; Cho, H.; Koka, S.; Agrawal, A. ArcGIS-SWAT: A geodata model and GIS interface for SWAT. J. Am. Water Resour. Assoc. 2006, 42, 295-309. [CrossRef]

50. Huang, B.; Jiang, B. AVTOP: A full integration of TOPMODEL into GIS. Environ. Model. Softw. 2002, 17, 261-268. [CrossRef]

(C) 2019 by the authors. Licensee MDPI, Basel, Switzerland. This article is an open access article distributed under the terms and conditions of the Creative Commons Attribution (CC BY) license (http://creativecommons.org/licenses/by/4.0/). 